\title{
Developmental toxicity of PAH mixtures in fish early life stages. Part II: adverse effects in Japanese medaka
}

\author{
Florane Le Bihanic ${ }^{1}$, Christelle Clérandeau ${ }^{1}$, Karyn Le Menach ${ }^{1}$, Bénédicte Morin ${ }^{1}$, Hélène Budzinski ${ }^{1}$, \\ Xavier Cousin ${ }^{2,3}$, Jérôme Cachot ${ }^{1, *}$
}

\author{
${ }^{1}$ UMR CNRS 5805 EPOC, University of Bordeaux, avenue des Facultés, 33405, Talence Cedex, France \\ 2 IFREMER, Ecotoxicology laboratory, Place Gaby Coll, BP7, 17137, L'Houmeau, France \\ ${ }^{3}$ INRA LPGP, Campus de Beaulieu, 35042, Rennes, France \\ *: Corresponding author : Jérôme Cachot, j.cachot@epoc.u-bordeaux1.fr
}

\begin{abstract}
:
In aquatic environments, polycyclic aromatic hydrocarbons (PAHs) mostly occur as complex mixtures, for which risk assessment remains problematic. To better understand the effects of PAH mixture toxicity on fish early life stages, this study compared the developmental toxicity of three PAH complex mixtures. These mixtures were extracted from a $\mathrm{PAH}$-contaminated sediment (Seine estuary, France) and two oils (Arabian Light and Erika). For each fraction, artificial sediment was spiked at three different environmental concentrations roughly equivalent to $0.5,4$, and $10 \mu \mathrm{g}$ total $P A H g^{-1} \mathrm{dw}$. Japanese medaka embryos were incubated on these PAH-spiked sediments throughout their development, right up until hatching. Several endpoints were recorded at different developmental stages, including acute endpoints, morphological abnormalities, larvae locomotion, and genotoxicity (comet and micronucleus assays). The three $\underline{\mathrm{PAH}}$ fractions delayed hatching, induced developmental abnormalities, disrupted larvae swimming activity, and damaged DNA at environmental concentrations. Differences in toxicity levels, likely related to differences in $\underline{P A} H$ proportions, were highlighted between fractions. The Arabian Light and Erika petrogenic fractions, containing a high proportion of alkylated PAHs and low molecular weight PAHs, were more toxic to Japanese medaka early life stages than the pyrolytic fraction. This was not supported by the toxic equivalency approach, which appeared unsuitable for assessing the toxicity of the three PAH fractions to fish early life stages. This study highlights the potential risks posed by environmental mixtures of alkylated and low molecular weight PAHs to early stages of fish development.
\end{abstract}

Keywords: Developmental abnormalities ; Comet assay ; Micronucleus assay ; Larvae locomotion ; Oil extract ; Pyrolytic extract ; Medaka embryo-larval assay 


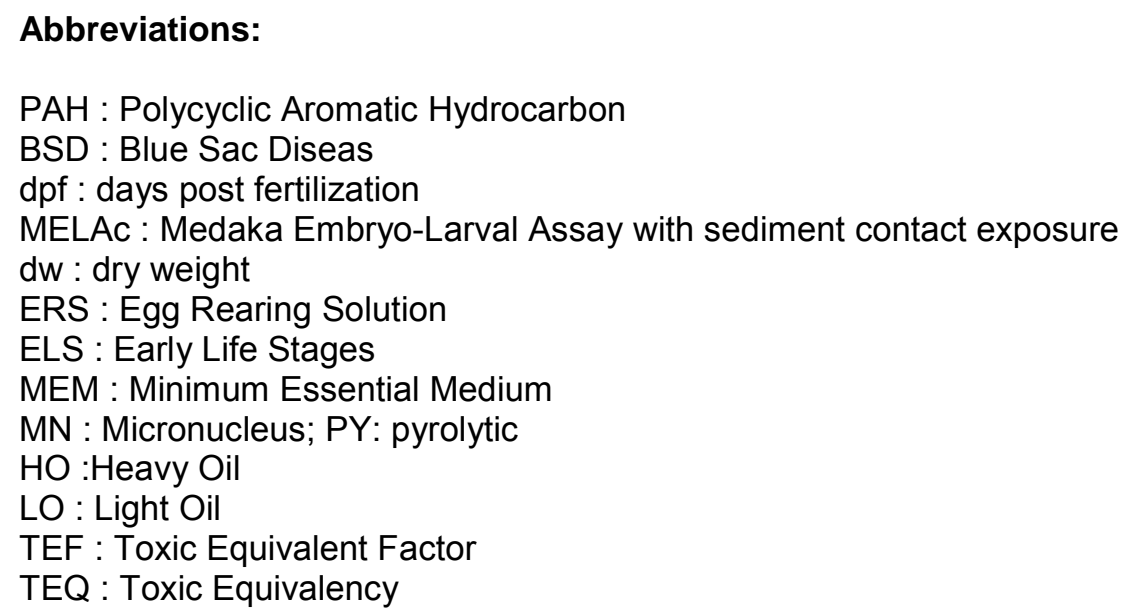

$\mathrm{PAH}$ : Polycyclic Aromatic Hydrocarbon

BSD : Blue Sac Diseas

dpf : days post fertilization

MELAc : Medaka Embryo-Larval Assay with sediment contact exposure

dw : dry weight

ERS : Egg Rearing Solution

ELS : Early Life Stages

MEM : Minimum Essential Medium

$\mathrm{MN}$ : Micronucleus; PY: pyrolytic

$\mathrm{HO}:$ Heavy Oil

LO : Light Oil

TEF : Toxic Equivalent Factor

TEQ : Toxic Equivalency

\section{Introduction}

While environmental contamination by polycyclic aromatic hydrocarbons (PAHs) is steadily increasing, assessing the actual risk posed by this contamination is problematic. In fact, PAHs occur mostly in complex mixtures in aquatic environments. Different methods have been proposed to assess the combined effects of these compounds. Assuming dose additivity, the concept of toxic equivalency was initially developed to evaluate the risk of dioxin-like compounds (Van den Berg et al. 2006; Safe 1993). This method consists of grading the toxic potency of different compounds based on a single reference toxicant. Toxic equivalent factor (TEF) values based on dioxin assume that effects are mediated by binding to the aryl hydrocarbon receptor (AhR), a cytosolic transcription factor (Barron et al. 2004b). TEF values, using benzo[a]pyrene as a reference, focus on the carcinogenic properties of the studied compounds (Nisbet and LaGoy 1992). However, some recent studies have reported toxicity of some weak AhR agonist PAHs that was independent of AhR activation (Incardona et al. 2006). This calls into question complex PAH mixture assessment based on toxic equivalencies. Furthermore the weak solubility of PAHs is also problematic to assess their toxicity to aquatic organisms. Indeed, waterborne exposure to these hydrophobic compounds is limited, and does not reflect their actual bioavailability in natural conditions (Hollert et al. 2003; Kiparissis et al. 2003). 

calls for the replacement, reduction, and refinement of the use of animals for scientific purposes (EC 2006). Fish embryo larval assays fulfill ethical requirements, providing an alternative to non-mammalian models (Embry et al. 2010; Strähle et al. 2012). Moreover, the transparency of the chorion enables direct and non-invasive observations during embryogenesis. Toxic effects of PAHs on fish early life stages (ELS) generally include both genotoxic and developmental effects. A common syndrome reported in dioxin and PAH-exposed fish embryos is Blue Sac Disease (BSD), which is characterized by pericardial and peritoneal edema, spinal curvature, craniofacial abnormalities, or altered heart development (Rhodes et al. 2005; Kim and Cooper 1999). It has previously been shown that pyrolytic PAH mixtures from contaminated sediment in the Seine River induced BSD - as well as mutations and tumors — in the transgenic Japanese medaka Lambda cII (Cachot et al. 2007). Petrogenic PAH mixtures also led to BSD, along with genetic damage and mortality among different species of fish embryos. (Couillard 2002; Carls et al. 1999; Colavecchia et al. 2004).

The MELAc (Medaka Embryo Larval Assay with sediment contact exposure) was selected in this study to improve and complement the risk assessment of hydrophobic compounds. (Vicquelin et al. 2011). The objective of our work was firstly to evaluate and compare the toxicity of three PAH fractions with different compositions: (i) a pyrolytic fraction (PY) from a contaminated sediment, (ii) a petrogenic PAH fraction from a heavy oil Erika (HO), (iii) and a second petrogenic PAH fraction from a type of light crude oil, Arabian Light (LO). Several endpoints were recorded, including survival, hatching delay, hatching success, abnormalities, larvae swimming activity, and DNA damages (comet and micronucleus assay). The micronucleus assay was carried out for the first time on cells extracted from the entire larvae in order to evaluate DNA damages in the whole body and not in a specific tissue.

Strong relationship has been shown between the results of acute toxicity tests in adults and in embryos for several fish model species (reviewed by Belanger et al., 2013). It is thereby questionable if the results obtained in this study can be extrapolated to other species. This is an important question since different model species are used in fish ELS assays (see for instance OECD's guidelines 212). Therefore an attempt was made in this study to compare ELS toxicity patterns and sensitivity between Japanese medaka (the present study) and another model fish, rainbow trout (Le Bihanic et al. this issue, in revision).

\section{MATERIALS \& METHODS}




\subsection{PAH fraction samples}

83 The pyrolytic PAH fraction (PY) was extracted from contaminated sediment in the Seine River, sampled in March 2010 in Oissel (Normandy, France). CEDRE (Center of Documentation, Research and Experimentation on Accidental Water Pollution) provided both the Arabian Light crude Oil (LO) and the Erika Heavy Oil (HO).

\section{(}

\subsection{Artificial sediment spiking}

The artificial sediment was composed of $92.5 \%$ silica sand, $2.5 \% \mathrm{dw}$ Sphagnum blond peat and $5 \%$ kaolin clay (Le Bihanic et al. this issue, in press). For each PAH fraction, the sediment was spiked to achieve $0.3 \mathrm{X}, 1 \mathrm{X}$ and 3X concentrations, with dichloromethane as a solvent (Biosolve, Valkenswaard, the Netherlands). 1X concentration refers to the sum of PAHs in sediments from the upper Seine estuary of $10 \mu \mathrm{g} \mathrm{g}^{-1}$ (Cachot et al. 2006). In fact, due to the relatively moderate sorption efficiency of PAHs on particles, the actual PAH concentrations in sediments were much lower. Measured PAHs included 21 non substituted PAHs (naphthalene, acenapthylene, acenaphthene, fluorene, dibenzo[$[b d]$ thiophene, phenanthrene, anthracene, fluoranthene, pyrene, benz $[a]$ anthracene, triphenylene, chrysene, benzo[b]naphto[2,1-d]thiophene, benzo $[b+k+j]$ fluoranthene, benzo $[e]$ pyrene, benzo $[a]$ pyrene, perylene, indeno[1,2,3-cd]pyrene, dibenzo $[a h]$ anthracene, dibenzo[ $a c]$ anthracene, benzo[ghi]perylene), methyl naphthalenic and methyl phenanthrenic compounds. PAHs spiked onto sediment were extracted using microwaves. PAHs were analyzed by gas chromatography coupled with mass spectrometry. Spiking and PAH analysis methods are detailed in (Le Bihanic et al. this issue, in press). 


\subsection{Embryo exposure}

Gis-Amagen (INRA, Jouy-en-Josas, France) provided eggs at early gastrula. One day post fertilization (dpf) embryos were placed onto the spiked sediment surface throughout embryonic development and until hatching.

The exposure unit, replicated 3 times for each treatment, contained 25 embryos, $3 \mathrm{~g} \mathrm{dw}$ of sediment and $3 \mathrm{~mL}$ of Egg Rearing Solution (ERS). Experiments took place in climate chamber (Snidjers Scientific, Tilburg, Netherlands) at $26 \pm 0.3{ }^{\circ} \mathrm{C}$ with a photoperiod light: dark of $12 \mathrm{~h}: 12 \mathrm{~h}, 5000 \mathrm{~lx}$ white light. Dissolved oxygen concentration in ERS medium was measured daily using a Fibox 3 fiber-optic oxygen mini-sensor (PreSens Precision Sensor, Regensburg, Germany). Exposure was stopped at the peak of hatching, when more than half of individuals hatched in the three replicates of a single condition (11 dpf for experiment 1 and $12 \mathrm{dpf}$ for experiment 2). After hatching, yolk-sac larvae were observed and transferred into glass beakers containing 20 $\mathrm{mL}$ of a water mixture (dechlorinated water mixed with distilled water 1:2 v/v aerated for $24 \mathrm{~h}$ ). After exposure, non-hatched embryos were transferred into new plastic Petri dishes containing $3 \mathrm{~mL}$ ERS without sediment. Yolk-sac larvae were not fed during the experiment. Three days after the peak hatching period, the experiment was stopped by euthanizing all remaining larvae and embryos with a lethal dose of $120 \mathrm{mg} \mathrm{L}^{-1}$ ethyl 4aminobenzoate (Sigma-Aldrich, St Quentin Fallavier, France). For convenience, toxicity tests on PAH fractions were divided into two experiments. The first experiment assessed PY PAH fraction toxicity, while the second focused on LO and HO PAH fraction toxicity. The two experiments were conducted under identical conditions.

\subsection{Phenotypic effect measurements}

Dead embryos and larvae were recorded daily and immediately removed to avoid alteration of the medium. Embryos that died within the first $24 \mathrm{~h}$ of the test $(0$ to $4 \%)$ were not taken into consideration for our calculations, as their death was likely to have been due to transportation stress. Heartbeat measurements were taken at room temperature $\left(23 \pm 1{ }^{\circ} \mathrm{C}\right)$ from $7 \mathrm{dpf}$ embryos. Heartbeats were measured over three 20 -second periods for the same embryo, using a Leica (Nanterre, France) MZ7.5 25x microscope and cold light source (Intralux ${ }^{\circledR}$ 4100, Volpi AG, Schlieren, Switzerland). Values were summed to obtain cardiac activity measurements in beat $\min ^{-1}$ for each embryo. Five individuals were analyzed per replicate. The time for $50 \%$ hatching was reported as hatching $\mathrm{T}_{1 / 2}$. Head length, total body length, and yolk sac area were measured between 0 and $24 \mathrm{~h}$ after hatching, on 15 randomly selected larvae per condition. Yolk sac area was measured as the 
abdominal cavity excluding the swim bladder area and the pericardial area. Swim bladder inflation was also reported. These measurements were taken using a Leica MZ7.5 stereomicroscope with Leica Microsystems software v3.8 (Nanterre, France).

At hatching, fifteen randomly selected larvae per replicate were individually examined to record morphological abnormalities and lesions. Observed larvae were photographed at 25X magnification using a Leica MZ7.5 stereomicroscope coupled with a Leica DFP420C CCD camera (Nanterre, France). Five types of abnormalities and lesions were scored: edema (peritoneal and pericardial); body (scoliosis, lordosis, kyphosis, and fin erosion); craniofacial (jaw and skull abnormalities); ocular (missing eye, cyclopia and dystrophy); cardio-vascular (anemia, hemorrhage, ventricle size, blood circulation, heart position). Abnormalities were scored on a scale of 1 to 5 (i.e. 1 point per type of abnormality). One larva could exhibit several abnormality types and/or several abnormalities of the same type (counted once). The percentage of abnormal larvae represented the number of larvae presenting at least one abnormality compare to the total number of examined individuals.

\subsection{Genotoxicity assays}

Comet and micronucleus assays (MN) were performed on the same cell suspension obtained from 10 larvae per replicate at 3 days post-hatching (dph). Cell isolated from larvae exposed to solvent sediment were used as negative controls for both assays. Cells were isolated based on a slightly modified version of the method developed by Morin et al. (2011) to enable sufficient number of isolated cells for both assays. Larvae were entirely minced with razor blades, and then digested at $37{ }^{\circ} \mathrm{C}$ for $45 \mathrm{~min}$, under slight agitation $(150 \mathrm{rpm})$ with $1.25 \mathrm{mg} \mathrm{mL}^{-1}$ dispase II from Bacillus polymyxa (Roche, Meylan, France) in Minimum Essential Medium Eagle (MEM) (Sigma-Aldrich, St Quentin Fallavier, France). Following centrifugation at $1000 \mathrm{rpm}$ for $10 \mathrm{~min}$ at room temperature, pellets were rinsed in $1 \mathrm{~mL}$ of MEM. Cell viability was assessed under a microscope, using the Trypan blue exclusion protocol. Cell suspension viability was above $95 \%$ in all samples, while cell density varied between $1300-4900$ cell $\mu \mathrm{L}^{-1}$.

64 For the comet assay, the protocol of Morin et al. (2011) was followed. Slides were covered with normal melting point agarose $1 \% \mathrm{w} / \mathrm{w}$. Two $50 \mu \mathrm{L}$ gels were laid on slides. The gels were composed of cell suspension of about 500 cell $\mu \mathrm{L}^{-1}$ and $1 \% \mathrm{w} / \mathrm{w}$ low melting point agarose. After gel hardening and $1 \mathrm{~h}$ lysis at $4{ }^{\circ} \mathrm{C}$, slides were placed on an electrophoresis tray and covered with a freshly prepared electrophoresis buffer for $10 \mathrm{~min}$, to allow 
168 the DNA to unwind. Electrophoresis was carried out at $25 \mathrm{~V}, 300 \mathrm{~mA}$ for $10 \mathrm{~min}$. After rinsing, slides were dehydrated in absolute ice-cold ethanol for a further $20 \mathrm{~min}$. Before reading, slides were stained with ethidium bromide $\left(20 \mu \mathrm{g} \mathrm{mL}^{-1}\right)$. Comet analysis was performed at X400 magnification using an Olympus epi-fluorescent microscope (Olympus, Rungis, France) and a grayscale CCD camera (Zeiss, Germany). DNA damage was measured at 100 nuclei per sample using Comet Assay IV (Perceptive instruments, Bury St Edmunds, UK) using blind review analysis. Data was expressed as percentage tail DNA.

For the MN assay, cell suspensions were fixed in a mixed solution of acetic acid: methanol 1:4 v/v, and smeared onto slides for a final concentration of 5000 cell $\mu \mathrm{L}^{-1}$. Slides were dried overnight at room temperature. Just before reading, slides were stained with an acridine orange solution (0.003\% in PBS) and cover with a glass slip. Readings were obtained using an epifluorescent microscope at X400 magnification (Olympus, Rungis, France). The frequency of micronucleated cells was manually recorded for 1000 cells per slide, using blind review analysis by a single observer. A cell was considered micronucleated if the $\mathrm{MN}$ was round-shaped, distinct from the main nucleus, its size was less than a third of the main nucleus, and with a similar green staining to the main nucleus (Hayashi et al. 1998). Cells that were non-isolated, stacked, more than bi-nucleated, or orange-red stained were excluded from the test. The MN assay performed on the whole body of larvae and used in the present study is under the rights of the French patent No.1058505 established 19/10/2010.

\subsection{Locomotion assay}

Our locomotion assay consisted of visual motor response measurements at 4 dph on 12 larvae per treatment replicate. The procedure was adapted from Emran et al. (2008) and Vignet at al. (2013). Larvae were randomly selected and placed into 48 -well microplates. Each microplate well contained 1 larva in $500 \mu \mathrm{L}$ of mixed water. Larvae were first acclimated for $1 \mathrm{~h}$ in the dark at room temperature $\left(23 \pm 1{ }^{\circ} \mathrm{C}\right)$. Coordinates were then recorded using an IR digital video camera (Ikegami Electronics, Neuss, Germany) for a 50 min analysis cycle in a Daniovision chamber (Noldus, Wageningen, Netherlands). This 50 min cycle included three periods of 20 min dark, 10 min light, and 20 min dark. Measurements were performed at $23 \pm 1{ }^{\circ} \mathrm{C}$ using Ethovision 9.0 (Noldus, Wageningen, the Netherlands). Dynamic subtraction methods were applied with a sampling rate of 25 per sec, dark contrast 16-255, current frame weight 4 , subject size 2-12500, and no subject contour dilation. To limit background noise, an input filter of minimal distance moved was set at $10 \%$ of the total body larva equivalent to $0.4 \mathrm{~mm}$. Mean velocity, distance swum, and mobility were calculated for each larva and for each light and dark 
197 period. Mobility refers to the time period for the totality of the larva area being modified even if the central point did not change. When an area of more than $60 \%$ changed for a given larva, that specimen was considered highly mobile. All microplates were analyzed at identical temperature, detection and acquisition settings. Larvae unable to swim because of morphological abnormalities were not taken into consideration for the locomotion assay.

\subsection{Statistics}

Each condition treatment was identically replicated three times. Each replicate was considered as an independent sample. Since only individuals from two replicates hatched for the $1 \mathrm{X}$ LO treatment, $\mathrm{N}=2$ for endpoints measured on $1 \mathrm{X}$ LO-exposed larvae. Normality of the data distribution was tested on data residues using the Shapiro-Wilk test $(p<0.01)$. Variance homogeneity was evaluated using the Levene test $(p<0.05)$. In case of homogenous variance and normalized data, one-way Anova analysis was performed, followed by the Tukey post-hoc test $(\mathrm{p}<0.05)$. In converse cases, data were analyzed using the Kruskal-Wallis non-parametric test $(\mathrm{p}<$ 0.05). Since hatching rate data distribution of petrogenic-exposed individuals was platykurtic, data underwent an arcsine transformation prior to statistical analysis (Legendre and Legendre 1998). Statistical analyses were performed with Statistica software v7.1 (StatSoft, Maisons-Alfort, France).

\subsection{Toxic equivalency}

214 TEQ were calculated regarding two different reference compounds: 2,3,7,8-tetrachlorodibenzo- $p$-dioxin (dioxin) 215 as reviewed by (Barron et al. 2004b) and benzo[a]pyrene as described by (Nisbet and LaGoy 1992) and 216 reviewed by (INERIS 2003). In the case of mixtures, TEF values are summed and weighted by the proportion of 217 the compound in a given mixture. Only the 16 USEPA PAHs were taken into consideration for this calculation. 218 Concentrations of benzo[j]fluoranthene, dibenzo[ah]anthracene and triphenylene were also included in calculation because they co-eluted with US EPA PAHs.

\section{RESULTS}

\subsection{PAH concentrations in spiked sediments}


Spiking efficiencies ranged between 17 and $43 \%$ (Table 1). Some PAH molecules were lost during the spiking

1 process, particularly naphthalene and methylnaphthalenic compounds. PAH concentrations in spiked sediments were comparable between fractions, and ranged from 0.5 to $0.8 \mu \mathrm{g} \mathrm{g}^{-1}$ for $0.3 \mathrm{X}$, from 3.6 to $4.0 \mu \mathrm{g} \mathrm{g}^{-1}$ for $1 \mathrm{X}$, and from 7.3 to $11.9 \mu \mathrm{g} \mathrm{g}^{-1}$ for $3 \mathrm{X}$. In contrast, PAH were detected at a very low concentration in control sediment. Alkylated PAH represented about $60 \%$ of measured PAH in LO sediment, $40 \%$ in HO sediment and less than $10 \%$ in PY sediment. Dissolved oxygen concentration was in average over $85 \%$ in all exposure units.

\subsection{Acute toxicity}

No significant embryonic or larval mortality was observed during exposure to any of the treatments tested (Table 2). For solvents, $0.3 \mathrm{X} \mathrm{LO}, 0.3 \mathrm{X} \mathrm{HO}$ and all PY conditions, hatching rate was above $88 \%$. However, only $28 \%$ of embryos exposed to $1 \mathrm{X}$ of the LO fraction hatched and less than $2 \%$ of $3 \mathrm{X} \mathrm{LO}, 1 \mathrm{X} \mathrm{HO}$ and $3 \mathrm{X}$ HO hatched during the experiment. Those last three treatments were therefore not considered for the following observations.

\subsection{Developmental effects}

No treatment effects were observed on embryonic heartbeat or swim bladder inflation in larvae at hatching (Table 2). The two oil fractions did not affect the kinetic of embryo development, although $3 \mathrm{X}$ PY treatment significantly delayed larvae $T_{1 / 2}$ hatching up to 1.1 day. There was no significant difference in yolk sac area between the exposed larvae and the solvent control group. In contrast, exposure to PAH fractions significantly reduced the head length and total length of exposed individuals. Total length was reduced by $0.2 \mathrm{~mm}$ for $3 \mathrm{X}$ PY, $0.3 \mathrm{~mm}$ for $0.3 \mathrm{X} \mathrm{LO}$ and $0.3 \mathrm{X} \mathrm{HO}$, and by $0.7 \mathrm{~mm}$ for $1 \mathrm{X} \mathrm{LO}$. The control larvae abnormality rate ranged between 9 and $18 \%$. All three PAH fractions induced teratogenicity in medaka ELS. On average, half of $0.3 \mathrm{X}$ LO-exposed larvae and all larvae exposed to $1 \mathrm{X}$ LO were abnormal. Although not significantly different from the control group, about a third of individuals exposed to $0.3 \mathrm{X}$ HO exhibited developmental anomalies. The frequency of deformed larvae increased from 11 to $62 \%$, while PY fraction increased from $0.3 \mathrm{X}$ to $3 \mathrm{X}$. The spectrum of abnormalities highlighted craniofacial abnormalities as appearing the most frequently. 3X PY larvae presented significantly higher rates of edemas, craniofacial, and cardiovascular abnormalities than control larvae. Larvae exposed to $1 \mathrm{X}$ LO displayed significant increases in edemas, spinal, craniofacial, and cardio-vascular abnormalities when compared to the control group. Although PAH concentrations in sediment for a given dose were similar for the three fractions, occurrences of abnormalities were different. Figure 1 presents photographs 
252 of the different developmental defects observed in medaka larva exposed to PAH fractions. Larvae exposed to

1

2253

3

0.3X petrogenic fractions presented several developmental defects, including changes in jaw and spinal curvature. This was comparable to $1 \mathrm{X}$ PY treatment effects. Edemas and cardio-vascular anomalies were induced by $1 \mathrm{X}$ LO. This was comparable to $3 \mathrm{X}$ PY treatment effects.

\subsection{Genotoxicity}

The comet assay did not reveal any significant DNA damage to cells from larvae treated with PAH fractions (Fig 2A). Cells from the control larvae presented 2 and $8 \%$ of tail DNA. In contrast, the MN assay highlighted a significant increase in DNA damage to larvae exposed to PY fractions at all concentrations, and in 0.3X LOtreated larvae (Fig 2B). Exposure to $0.3 \mathrm{X}$ HO tended to increase the MN frequency for treated larvae, although this was not significant. MN cell frequency in controls ranged between 2.3 and $3.7 \%$.

\subsection{Locomotion effects}

Figure 3 shows the effects of PAH fractions on larvae velocity under dark and light challenges. All larvae followed a similar pattern. After a slight decrease from 0 to $5 \mathrm{~min}$, larvae velocity stabilized and was constant during the first dark period ( 0 to $20 \mathrm{~min}$ ). When the light was turned on for a $10 \mathrm{~min}$ period (20 to $30 \mathrm{~min}$ ), larvae activity was slightly increased. In contrast, when the light was extinguished after 30 min, all larvae reacted with a 3-5 fold increase in velocity. Larva velocity then progressively decreased back down to the level of the first dark period. Larvae exposed to PAH fractions swam faster and over longer distances than control larvae. Indeed, 3X PY larvae swam 1.9 times more than control larvae during the first dark period (Fig. 4A). Larvae exposed to $0.3 \mathrm{X} \mathrm{LO}$ swam 1.9 times more during the first dark period and 1.3 times more during the light period (Fig. 4B). And 0.3X HO larvae swam 1.6 times more during the first dark period. Based on results relating to velocity and distance swum, PAH-exposed larvae were more mobile than control larvae. This was significant for $3 \mathrm{X}$ PY larvae, which were 2.5 times and 1.9 times more mobile than control larvae during the first dark and light periods respectively (Fig. 4C). $0.3 \mathrm{X} \mathrm{LO}$ larvae were 2.6 and 1.6 times more mobile than control larvae during the two dark periods (Fig. 4D). 


\subsection{Toxic equivalency}

Table 3 presents the TEQs of the three PAH mixtures regarding both benzo[a]pyrene and dioxin. In contrast to the observed toxicity on fish ELS described above, these two methods of calculation display the PY fraction as being the most toxic to fish. The PY TEQ value was twice (BaP) and four times (dioxin) as high as the HO fraction. The LO fraction would therefore appear to be the least potent toxic fraction, with a TEQ value nine times (BaP) and five times (regarding dioxin) lower than the HO fraction.

\section{DISCUSSION}

In our study, the toxicity of the three different PAH mixtures was evaluated in ELS of Japanese medaka. The experiments satisfied the recommendations set out in the OECD's guidelines for embryo-larval assays in terms of dissolved oxygen concentration (OECD 1992). Survival, heartbeat, biometry, developmental abnormality rate, DNA damages and larval locomotion of control individuals were within a similar range to that observed in previous studies (Morin et al. 2011; Vicquelin et al. 2011). Variability between experiment 1 and 2 of abnormal larvae and tail DNA percentages in controls could be explained by natural biological variations between the different batches of eggs. This natural variability was already reported and discussed (Lebihanic et al. this issue, in press). Exposure to the two petrogenic fractions induced lethal effects by preventing individuals from hatching before the end of the experiment at $1 \mathrm{X}$ and $3 \mathrm{X}$ concentrations. Dimethyl-PAHs and weathered crude oil were also shown to prevent hatching of Japanese medaka embryos and pink salmon embryos (Rhodes et al. 2005; Carls and Thedinga 2010). Numerous developmental effects, such as reduced growth, edemas, anemia, hemorrhages, cessation of blood flow and body axis deformities were recorded. The spectrum of effects observed was very similar to the BSD syndrome previously reported in medaka embryos exposed to various PAHs (Rhodes et al. 2005; Vicquelin et al. 2001). Kiparissis et al. (2003) reported edemas, craniofacial deformities, and impaired circulation following embryonic exposure to retene. Mummichog embryos exposed to crude oil contaminated sediment also exhibited reduced body length, pericardial edema, hemorrhages, and spinal deformities (Couillard 2002). BSD syndrome was demonstrated to be triggered by different non-specific mechanisms, such as narcosis, or via interactions with specific receptors such as the AhR or cardiotoxicity (Billiard et al. 2008). This syndrome evidenced only part of the mode of action of PAH mixtures. The MN assay has been in use for several decades to assess genotoxicity in various fish contaminated with PAHs (Baršienė et al. 2006; Rocha et al. 2009). In this study, the MN assay was carried out for the first time on cells from entire 
larvae. This assay allowed global assessment of genotoxic damages in the whole body and not only in a specific tissue, as currently performed. It is thus a more valuable endpoint to assess the global health status of a given organism exposed to genotoxicants. MN was also analyzed on entire larvae. Data obtained highlighted irreversible DNA damage caused by two out of three PAH fractions, PY and LO. Similarly, Oreochromis niloticus exposed to petroleum refinery effluent exhibited micronuclei as well as bi-nucleate gill epithelial cells and erythrocytes, lobed nuclei, and notched nuclei that complemented MN scoring (Cavaș and Ergene-Gözükara 2005). PAH fractions also activated larvae locomotion both after stabilization of the larvae in dark and under light challenges. Irons et al. (2013) illustrated that fish larvae locomotion in response to chemicals depends on the compound and concentration. A possible explanation for changes to locomotion functions is that PAHs affect the neurotransmitter pathways (Gesto et al. 2009). Endocrine disruptor activities of PAHs have also already been reported (Barron 2002). Interferences of PAHs or their metabolites with hormone system could partly explain hyperactivity in contaminated larvae. Locomotion assays carried out on fish larvae represent a newly-expanding method which serves to complement toxicity analysis by providing an integrative response to broad physiological alterations, such as disruption of the central nervous system, vision, skeleton and muscles (de Esch et al. 2012).

One aim of this work was also to compare the sensitivity of two model species for the same three PAH fractions (PY, LO, and HO) at $0.3 \mathrm{X}$ concentration (Table 4). The toxicity of these three fractions was initially tested on Rainbow trout ELS (Le Bihanic et al. this issue, in revision), then tested on Japanese medaka (this study). PAHfractions and operators were identical, but comparison was limited by differences in exposure matrix, PAHspiked concentrations, time of exposure, rearing temperature, photoperiod, water renewal and salinity. This is relevant because it has been proved that certain light radiations enhance PAH toxicity, temperature increases dissolution of the compound, and salinity seems to raise PAH sorption (Barron et al. 2003; $\underline{\text { Turner and Rawling }}$ 2001; Faksness et al. 2008). Despite these differences, the PY fraction appeared to be the less toxic fraction for the two species. The two petrogenic fractions $\mathrm{LO}$ and $\mathrm{HO}$ fractions were shown to induce the majority of the effects on fish embryos and larvae. The PY fraction was mainly composed of 4-5 rings non-alkylated PAHs in opposition with the two petrogenic fractions, mainly composed of alkylated PAHs known to drive the developmental toxicity of PAH mixtures (Sundberg et al. 2005; Fallahtafti et al. 2012; Incardona et al. 2005). Several studies documented alkylated PAHs as more toxic than their non-alkylated homologs (Barron et al. 2004a; Turcotte et al. 2011). Exposure to PAH fractions impacted biometry, morphology and DNA integrity of both species. On one hand, medaka larvae exhibited DNA damages detected with the MN assay, which are 
338 chromosomal aberrations caused by clastogenic and aneugenic events. On the other hand, trout larvae presented only labile damages detected with the comet assay, such as single/double DNA strand breaks, alkali labile sites and excision/repair DNA damages. Medaka individuals develop faster than trout, meaning that their cells present a higher mitotic index. We can therefore hypothesize that DNA damages set quicker with medaka than it did with trout.

Several previous studies have compared toxicity responses exhibited by Japanese medaka and rainbow trout. On one hand relationship was identified between both species (Belanger et al., 2013), and on the other hand sensitivity was shown to vary between compounds. For endocrine disruptors, trout was more sensitive than medaka (Dobbins et al. 2008), while medaka appeared to be the more sensitive of the two when exposed to pulp and paper mill effluents (Orrego et al. 2011). When considering the three PAH fractions tested, rainbow trout ELS were significantly more sensitive to $\mathrm{HO}$ fraction than to LO, but this was not statistically evident for Japanese medaka. The main difference between these two petrogenic fractions is their proportion in alkylated naphthalene higher for LO, and alkylated phenanthrene higher for HO. Our study showed similar toxicity gradients for PAH mixtures between medaka and trout ELS but slight differences in toxic potency. Compared to studies performed on single model species, multi-species studies offer a more comprehensive and accurate risk assessment of chemicals. Further supplementary experiments using similar exposure conditions for both species would strengthen these results.

TEQ calculations were not consistent with the toxicity observed in fish ELS (Table 3). The PY fraction is considered the most potent toxic fraction for both methods of TEQ calculation, while it was the least toxic from the point of view of acute and sub-lethal toxicity on Japanese medaka and rainbow trout ELS. TEQ values depend on the mode of action considered: carcinogenicity or AhR agonist (Barron et al. 2004b; INERIS 2003). However, these methods do not consider other modes of action such as nonspecific toxicity or toxicity independent of the binding to AhR. Moreover, PAHs are different in terms of structure and bioaccumulation to dioxin (Billiard et al. 2008). In order to take into account PAH developmental toxicity on fish ELS, other TEF values are needed. Considering complex mixtures of PAHs, the toxic potency is a function of the components and their interactions. The TEQ approach to PAH mixture assessment is oversimplified, because it is based on the hypothesis of potency additivity, and does not consider possible synergistic or antagonistic interactions between molecules (Wassenberg \&Di Giulio 2004, Wassenberg et al. 2005). The findings described in our study do not support the TEQ approach. We may therefore assume that TEQ methods with the existing TEF values are not suitable for the toxicity assessment of complex PAH mixtures to fish ELS. 
2

\section{CONCLUSION}

Developmental toxicity, locomotion defects, and genotoxicity were all detected at PAH concentrations similar to those occurring in sediments from various European rivers and estuaries. Our results raise the question of the impact of PAH-contaminated sediments on survival and recruitment in fish ELS. The toxic equivalency approach was not suitable for predicting the developmental toxicity of PAHs mixtures. The range of induced toxicity differed between fractions tested. The LO and the HO petrogenic fractions, with high proportions in alkylated and low to medium molecular weight PAHs, were more toxic to Japanese medaka ELS than the PY fraction. This was consistent with a previous study carried out on rainbow trout ELS.

\section{ACKNOWLEDGMENTS}

379 This study was funded by the French National Agency for Research's "Contaminant, Ecosystème et santé" 380 program, as part of the ConPhyPoP (2009-002) research project. It was also included in the LABEX COTE 381 cluster of excellence for continental and coastal ecosystems. Following the project, Florane Le Bihanic received $\mathrm{PhD}$ fellowship from "Ministère de l'Enseignement Supérieur et de la Recherche". The authors wish to thank

CEDRE for providing oils, as well as Laure Landi for laboratory management.

\section{REFERENCES}

Barron MG (2002) Environmental Contaminants Altering Behaviour. In: Dell'Omo G (ed) Behavioural Ecotoxicology. John Wiley \& Sons Ltd, Chichester,

Barron MG, Carls MG, Short JW, Rice SD (2003) Photoenhanced toxicity of aqueous phase and chemically dispersed weathered alaska north slope crude oil to pacific herring eggs and larvae. Environ Toxicol Chem 22 (3):650-660

Barron MG, Carls MG, Heintz R, Rice SD (2004a) Evaluation of Fish Early Life-Stage Toxicity Models of Chronic Embryonic Exposures to Complex Polycyclic Aromatic Hydrocarbon Mixtures. Toxicol Sci 78 (1):60-67 
394 Barron MG, Heintz R, Rice SD (2004b) Relative potency of PAHs and heterocycles as aryl hydrocarbon receptor agonists in fish. Mar Environ Res 58 (2-5):95-100

Baršienė J, Dedonytė V, Rybakovas A, Andreikėnaitė L, Andersen OK (2006) Investigation of micronuclei and other nuclear abnormalities in peripheral blood and kidney of marine fish treated with crude oil. Aquat Toxicol 78, Supplement (0):S99-S104

Belanger SE, Rawlings JM, Carr GJ (2013). Use of fish embryo toxicity for the prediction of acute fish toxicity to chemicals. Environ Toxicol Chem 32 (8): 1768-1783

Billiard SM, Meyer JN, Wassenberg DM, Hodson PV, Di Giulio RT (2008) Nonadditive effects of PAHs on early vertebrate development: mechanisms and implications for risk assessment. Toxicol Sci 105 (1):5-23

Cachot J, Geffard O, Augagneur S, Lacroix S, Le Menach K, Peluhet L, Couteau J, Denier X, Devier MH, Pottier D, Budzinski H (2006) Evidence of genotoxicity related to high PAH content of sediments in the upper part of the Seine estuary (Normandy, France). Aquat Toxicol 79 (3):257-267

Cachot J, Law M, Pottier D, Peluhet L, Norris M, Budzinski H, Winn R (2007) Characterization of toxic effects of sediment-associated organic pollutants using the $\lambda$ transgenic medaka. Environ Sci Technol 41 (22):7830-7836

Carls MG, Rice SD, Hose JE (1999) Sensitivity of fish embryos to weathered crude oil: Part I. Low-level exposure during incubation causes malformations, genetic damage, and mortality in larval pacific herring (Clupea pallasi). Environ Toxicol Chem 18 (3):481-493

Carls MG, Thedinga JF (2010) Exposure of pink salmon embryos to dissolved polynuclear aromatic hydrocarbons delays development, prolonging vulnerability to mechanical damage. Mar Environ Res 69 (5):318-325

Çavaş T, Ergene-Gözükara S (2005) Induction of micronuclei and nuclear abnormalities in Oreochromis niloticus following exposure to petroleum refinery and chromium processing plant effluents. Aquat Toxicol 74 (3):264-271

Colavecchia MV, Backus S, Hodson PV, Parrott JL (2004) Toxicity of oil sands to early life stages of fathead minnows (Pimephales promelas). Environ Toxicol Chem 23 (7):1709-1718

Couillard CM (2002) A microscale test to measure petroleum oil toxicity to mummichog embryos. Environ Toxicol 17 (3):195-202. doi:10.1002/tox.10049

de Esch C, Slieker R, Wolterbeek A, Woutersen R, de Groot D (2012) Zebrafish as potential model for developmental neurotoxicity testing: A mini review. Neurotoxicol Teratol 34 (6):545-553. 
Dobbins LL, Brain RA, Brooks BW (2008) Comparison of the sensitivities of common in vitro and in vivo assays of estrogenic activity: application of chemical toxicity distributions. Environ Toxicol Chem 27 (12):2608-2616

EC (2006) Regulation (EC) $\mathrm{N}^{\circ} 1907 / 2006$ of the european parliament and of the concil concerning the Registration Evaluation and Authorization of Chemicals (REACh). vol L 396. Official Journal of the European Union,

Embry MR, Belanger SE, Braunbeck TA, Galay-Burgos M, Halder M, Hinton DE, Léonard MA, Lillicrap A, Norberg-King T, Whale G (2010) The fish embryo toxicity test as an animal alternative method in hazard and risk assessment and scientific research. Aquat Toxicol 97 (2):79-87

Emran F, Rihel J, Dowling JE (2008) A Behavioral Assay to Measure Responsiveness of Zebrafish to Changes in Light Intensities. Journal of Visualized Experiments (20):e923. doi:doi:10.3791/923

Faksness L-G, Brandvik PJ, Sydnes LK (2008) Composition of the water accommodated fractions as a function of exposure times and temperatures. Mar Pollut Bull 56 (10):1746-1754

Fallahtafti S, Rantanen T, Brown RS, Snieckus V, Hodson PV (2012) Toxicity of hydroxylated alkylphenanthrenes to the early life stages of Japanese medaka (Oryzias latipes). Aquat Toxicol 106-107 (0):56-64

Gesto M, Tintos A, Soengas JL, Míguez JM (2009) $\beta$-Naphthoflavone and benzo[a]pyrene alter dopaminergic, noradrenergic, and serotonergic systems in brain and pituitary of rainbow trout (Oncorhynchus mykiss). Ecotoxicol Environ Saf 72 (1):191-198.

Hayashi M, Ueda T, Uyeno K, Wada K, Kinae N, Saotome K, Tanaka N, Takai A, Sasaki YF, Asano N, Sofuni T, Ojima Y (1998) Development of genotoxicity assay systems that use aquatic organisms. Mutat ResFundam Mol Mech Mutag 399 (2):125-133

Hollert H, Keiter S, König N, Rudolf M, Ulrich M, Braunbeck T (2003) A new sediment contact assay to assess particle-bound pollutants using zebrafish (Danio rerio) embryos. J Soils Sed 3 (3):197-207. doi:10.1065/jss2003.09.085

Incardona JP, Carls MG, Teraoka H, Sloan CA, Collier TK, Scholz NL (2005) Aryl hydrocarbon receptorindependent toxicity of weathered crude oil during fish development. Environ Health Perspect 113 (12): $1755-1762$ 
Incardona JP, Day HL, Collier TK, Scholz NL (2006) Developmental toxicity of 4-ring polycyclic aromatic hydrocarbons in zebrafish is differentially dependent on $\mathrm{AH}$ receptor isoforms and hepatic cytochrome P4501A metabolism. Toxicol Appl Pharmacol 217 (3):308-321

INERIS (2003) Hydrocarbures Aromatiques Polycycliques (HAPs) Evaluation de la relation dose-réponse pour des effets cancérigènes: Approche substance par substance et approche par mélange - Evaluation de la relation dose-réponse pour des effets non cancérigènes: valeurs toxiques de référence. Institut national de l'environnement industriel et des risques, Verneuil-en-Halatte

Irons TD, Kelly PE, Hunter DL, MacPhail RC, Padilla S (2013) Acute administration of dopaminergic drugs has differential effects on locomotion in larval zebrafish. Pharmacol Biochem Behav 103 (4):792-813

Kim Y, Cooper KR (1999) Toxicity of 2,3,7,8-tetrachlorodibenzo-p-dioxin (TCDD) and polychlorinated biphenyls (PCBs) in the embryos and newly hatched larvae of the Japanese medaka (Oryzias latipes). Chemosphere 39 (3):527-538

Kiparissis Y, Akhtar P, Hodson PV, Brown RS (2003) Partition-Controlled Delivery of Toxicants: A Novel In Vivo Approach for Embryo Toxicity Testing. Environ Sci Technol 37 (10):2262-2266. doi:10.1021/es026154r

Le Bihanic F, Morin B, Cousin X, Le Menach K, Budzinski H, Cachot J (in revision) Developmental toxicity of PAH mixtures in fish early life stages. Part I : adverse effects in Rainbow T. Environ Sci Pollut Res this issue.

Le Bihanic F, Perrichon P, Le Menach K, Budzinski H, Cousin X, Cachot J (in press) Development of a reference artificial sediment for chemical testing adapted to the MELA sediment contact assay. Environ Sci Pollut Res this issue.

Legendre P, Legendre L (1998) Numerical Ecology. Elsevier Science BV, Amsterdam

Morin B, Filatreau J, Vicquelin L, Barjhoux I, Guinel S, Leray-Forget J, Cachot J (2011) Detection of DNA damage in yolk-sac larvae of the Japanese Medaka, Oryzias latipes, by the comet assay. Anal Bioanal Chem 399 (6):2235-2242. doi:10.1007/s00216-010-4602-y

Nisbet ICT, LaGoy PK (1992) Toxic equivalency factors (TEFs) for polycyclic aromatic hydrocarbons (PAHs). Regul Toxicol Pharmacol 16 (3):290-300.

OECD (1992) Guidelines for the testing of chemicals fish early life stage toxicity test, Test No. 210. Section 2: Effects on biotic systems. Organization for Economic Cooperation and Developpment, 
Orrego R, Guchardi J, Beyger L, Krause R, Holdway D (2011) Comparative embryotoxicity of pulp mill extracts in rainbow trout (Oncorhynchus mykiss), American flagfish (Jordanella floridae) and Japanese medaka (Oryzias latipes). Aquat Toxicol 104 (3-4):299-307.

Rhodes S, Farwell A, Mark Hewitt L, MacKinnon M, George Dixon D (2005) The effects of dimethylated and alkylated polycyclic aromatic hydrocarbons on the embryonic development of the Japanese medaka. Ecotoxicol Environ Saf 60 (3):247-258

Rocha PS, Luvizotto GL, Kosmehl T, Böttcher M, Storch V, Braunbeck T, Hollert H (2009) Sediment genotoxicity in the Tietê River (São Paulo, Brazil): In vitro comet assay versus in situ micronucleus assay studies. Ecotoxicol Environ Saf 72 (7):1842-1848

Safe S (1993) Development of Bioassays and approaches for the risk assessment of 2,3,7,8-tetrachlodibenzo-pdioxin and related compounds. Environ Health Perspect Suppl 101 (Suppl. 3):317-325

Strähle U, Scholz S, Geisler R, Greiner P, Hollert H, Rastegar S, Schumacher A, Selderslaghs I, Weiss C, Witters H, Braunbeck T (2012) Zebrafish embryos as an alternative to animal experiments - A commentary on the definition of the onset of protected life stages in animal welfare regulations. Reprod Toxicol 33 (2):128-132

Sundberg H, Ishaq R, Akerman G, Tjarnlund U, Zebuhr Y, Linderoth M, Broman D, Balk L (2005) A bio-effect directed fractionation study for toxicological and chemical characterization of organic compounds in bottom sediment. Toxicol Sci 84 (1):63-72. doi:10.1093/toxsci/kfi067

Turcotte D, Akhtar P, Bowerman M, Kiparissis Y, Brown S, Hodson PV (2011) Measuring the toxicity of alkylphenanthrenes to early life stages of medaka (Oryzias latipes) using partition-controlled delivery. Environ Toxicol Chem 30 (2):487-495

Turner A, Rawling MC (2001) The influence of salting out on the sorption of neutral organic compounds in estuaries. Water Res 35 (18):4379-4389

Van den Berg M, Birnbaum LS, Denison M, De Vito M, Farland W, Feeley M, Fiedler H, Hakansson H, Hanberg A, Haws L, Rose M, Safe S, Schrenk D, Tohyama C, Tritscher A, Tuomisto J, Tysklind M, Walker N, Peterson RE (2006) The 2005 World Health Organization Reevaluation of Human and Mammalian Toxic Equivalency Factors for Dioxins and Dioxin-Like Compounds. Toxicol Sci 93 (2):223-241

Vicquelin L, Leray-Forget Jl, Peluhet L, Le Menach K, Deflandre B, Anschutz P, Etcheber H, Morin B, Budzinski H, Cachot J (2011) A new spiked sediment assay using embryos of the Japanese medaka 
specifically designed for a reliable toxicity assessment of hydrophobic chemicals. Aquat Toxicol 105 (34):235-245

Vignet C, Bégout ML, Péan S, Lyphout L, Leguay D, Cousin X. (2013). Systematic screening of behavioral responses in two zebrafish strains. Zebrafish 10 (3):365-375.

Wassenberg DM, Di Giulio RT (2004): Synergistic embryotoxicity of polycyclic aromatic hydrocarbon aryl hydrocarbon receptor agonists with cytochrome P4501A inhibitors in Fundulus heteroclitus. Environ. Health Perspect. 112, 1658-1664

Wassenberg DM, Nerlinger AL, Battle LP, Giulio RTD (2005): Effects of the polycyclic aromatic hydrocarbon heterocycles, carbazole and dibenzothiophene, on in vivo and in vitro cypla activity and polycyclic aromatic hydrocarbon-derived embryonic deformities. Environ. Toxicol. Chem. 24, 2526-2532

\section{FIGURE CAPTIONS}

Figure 1. The PAH fractions induced teratogenicity in medaka larvae following embryo exposure to PAH-spiked sediment. A) No noticeable developmental abnormality in control larva; B) Jaw deformity and spinal curvature in $1 \mathrm{X}$ PY-exposed larva; C) Jaw and cranial deformities, pericardial and peritoneal edemas in 3X PY-exposed larva. White arrows indicate pericardial or peritoneal edemas. Black arrows indicate skeleton deformities either cranio-facial or spinal.

Figure 2. The PAH fractions induced genotoxicity following medaka embryo exposure to PAH-spiked sediments. Comet and micronucleus assays were performed on the same sample of cells obtained from the whole body of ten larvae. The different letters stand for significant differences between treatments (Mean $\pm \mathrm{SD}, \mathrm{N}=3$, Anova, $\mathrm{p}<0.05)$.

Figure 3. Medaka larvae velocity during 50 min video tracked analysis: 20 min dark +10 min light +20 min dark for 0.3X treated individuals. Embryos were exposed to PAH-spiked sediments. Data was averaged over each 1min interval. (Mean $\pm \mathrm{SD}, \mathrm{N}=3$ ).

Figure 4. The PAH fractions disrupted medaka larvae locomotion. Data was averaged out across each dark or light interval. Embryos were exposed to PAH-spiked sediment. The different letters stand for significant differences between treatments (Mean $\pm \mathrm{SD}, \mathrm{N}=3$, Anova, $\mathrm{p}<0.05$ ). 
Figure 1
Figures

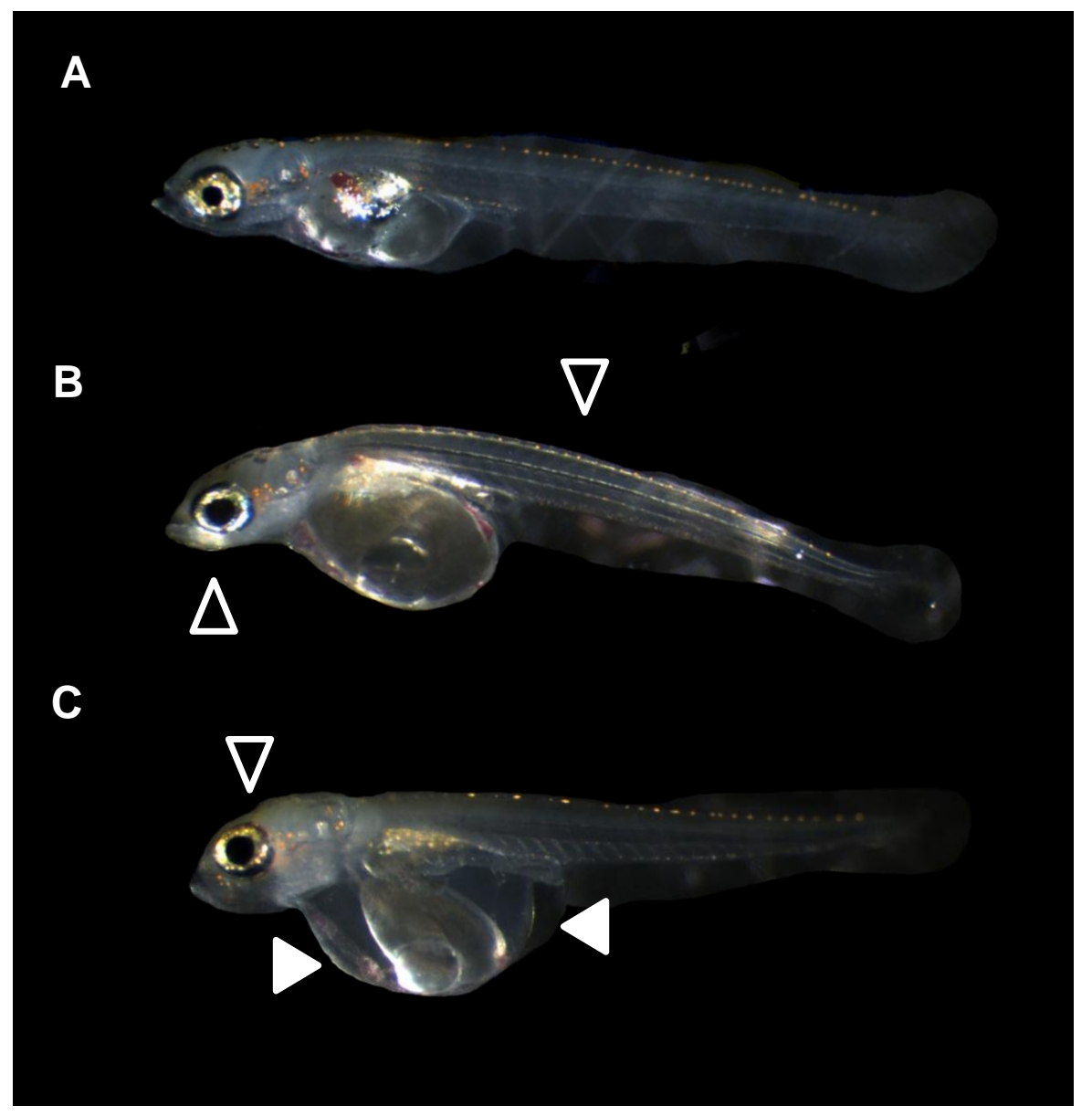

$$
\text { - b } 1
$$


Figure 2

A

Comet Assay

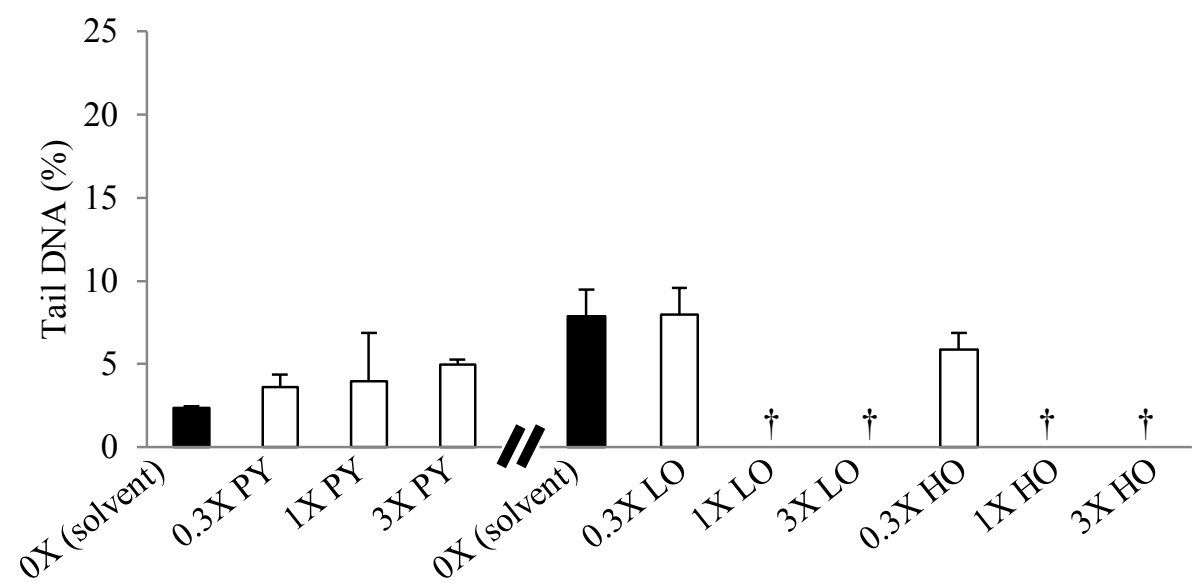

B

Micronucleus assay

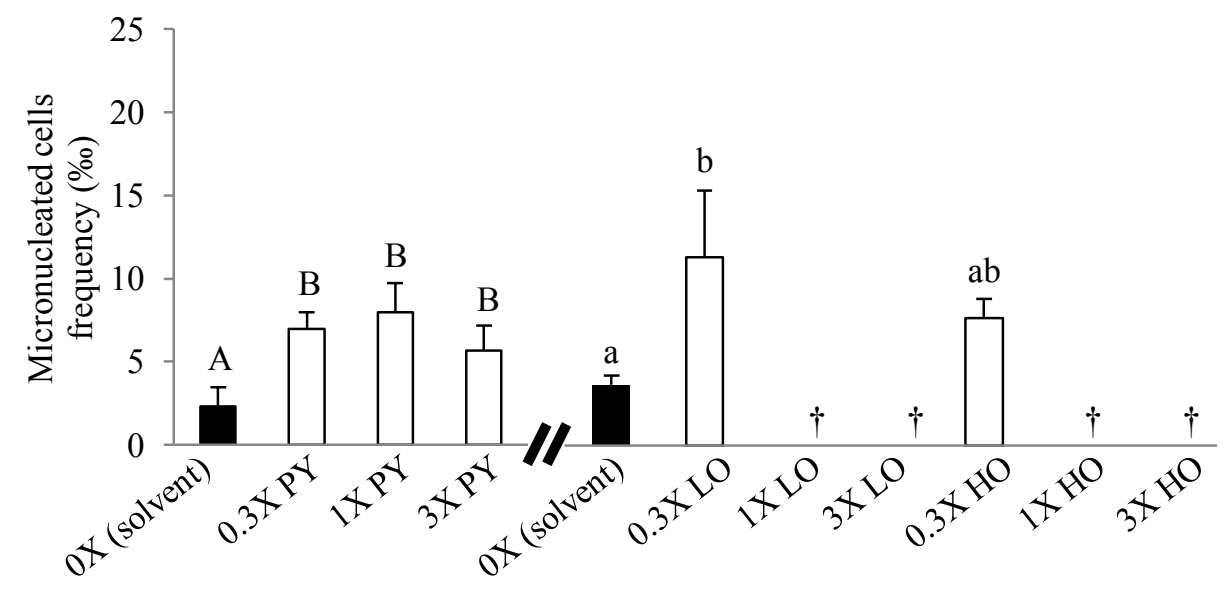




\section{Figure 4}
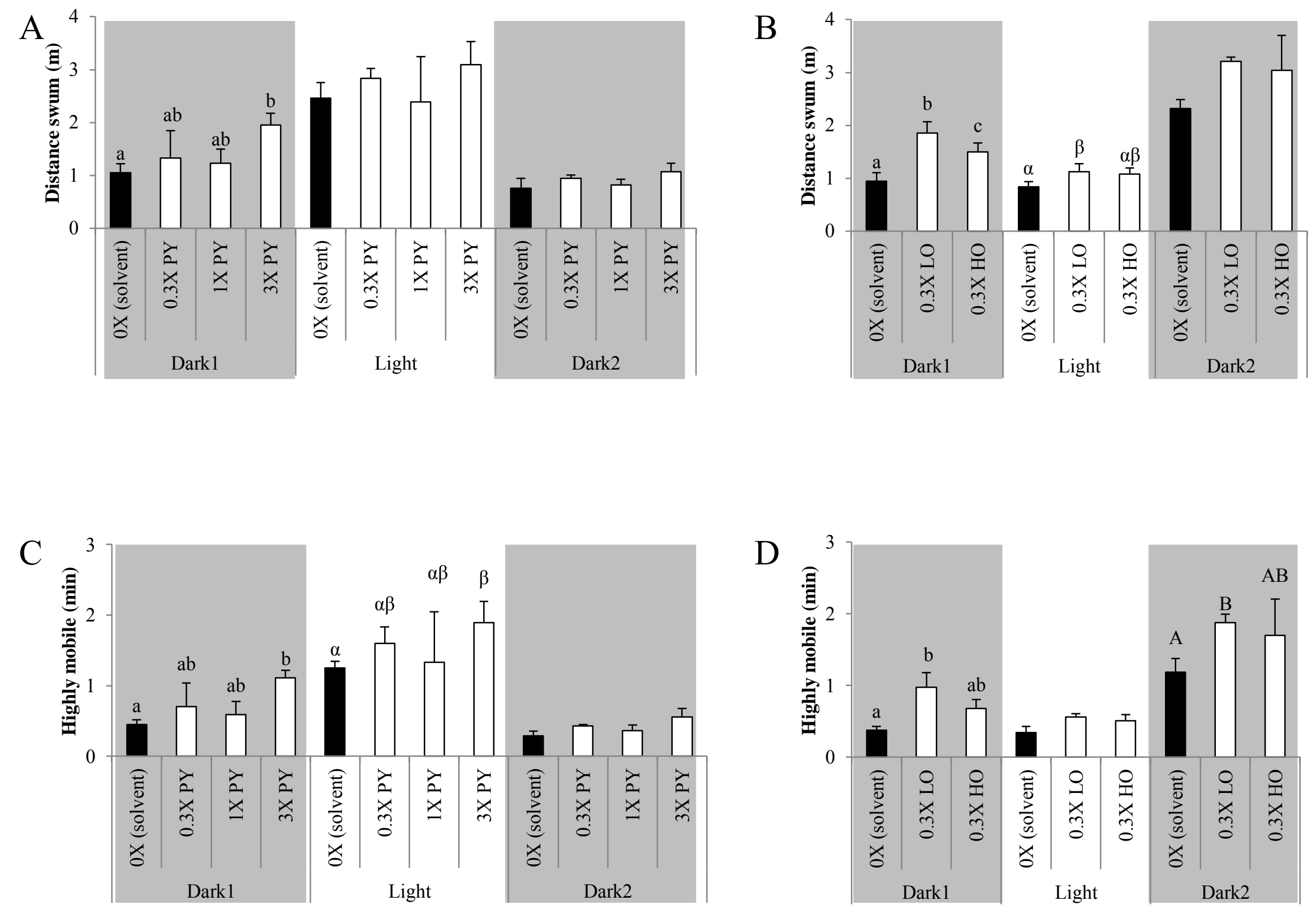
Table 1. Measured PAH concentrations and dissolved oxygen in the assays

\begin{tabular}{|c|c|c|c|c|c|c|c|c|c|c|c|}
\hline & \multicolumn{5}{|c|}{$\mathbf{P Y}$} & \multicolumn{3}{|c|}{ LO } & \multicolumn{3}{|c|}{ HO } \\
\hline & Solvent & $0.3 X$ & $\mathbf{1 X}$ & $3 \mathbf{X}$ & Solvent & $0.3 X$ & $\mathbf{1 X}$ & $3 \mathbf{X}$ & $0.3 X$ & $\mathbf{1 X}$ & $3 \mathbf{X}$ \\
\hline PAH concentration $\left(\mu \mathrm{g} \mathrm{g}^{-1}\right)(\mathrm{N}=1)$ & 0.022 & 0.816 & 3.862 & 11.779 & 0.009 & 0.499 & 3.618 & 7.253 & 0.717 & 4.039 & 11.929 \\
\hline Alkylated PAH $(\%)(\mathrm{N}=1)$ & - & 6 & 5 & 5 & - & 61 & 57 & 66 & 40 & 41 & 42 \\
\hline Spiking efficiency $(\%)(\mathrm{N}=1)$ & - & 27 & 39 & 39 & - & 17 & 38 & 25 & 26 & 43 & 43 \\
\hline Dissolved $\mathrm{O}_{2}(\%)($ Mean $\pm \mathrm{SD}, \mathrm{N}=3)$ & $90.0 \pm 2.4$ & $89.9 \pm 1.0$ & $88.3 \pm 2.1$ & $87.7 \pm 2.0$ & $87.2 \pm 1.3$ & $87.3 \pm 0.7$ & $85.9 \pm 0.7$ & $88.1 \pm 0.5$ & $86.9 \pm 0.5$ & $88.9 \pm 0.2$ & $88.0 \pm 0.9$ \\
\hline
\end{tabular}


Table 2. Developmental toxicity of the three PAH fractions after medaka embryos exposure to PAH-spiked sediments. Different letters and bold characters refer to significant differences between treatments (Mean $\pm \mathrm{SD}, \mathrm{N}=3$, Anova, $\mathrm{p}<0.05$ ).

\begin{tabular}{|c|c|c|c|c|c|c|c|c|c|c|c|}
\hline & \multicolumn{4}{|c|}{ Experiment 1} & \multicolumn{7}{|c|}{ Experiment 2} \\
\hline & Solvent & $0.3 X$ PY & 1X PY & 3X PY & Solvent & $0.3 \times$ LO & $1 \times$ LO & $3 \times \mathrm{LO}$ & $0.3 \times$ HO & 1X HO & $3 \mathrm{X} \mathrm{HO}$ \\
\hline $\begin{array}{l}\text { Acute Toxicity } \\
\text { Embryonic survival (\%) }\end{array}$ & $94.7 \pm 2.3$ & $97.2 \pm 4.8$ & $95.9 \pm 4.2$ & $100.0 \pm 0.0$ & $97.0 \pm 2.0$ & $93.3 \pm 5.0$ & $96.0 \pm 3.3$ & $97.3 \pm 1.9$ & $96.0 \pm 3.3$ & $98.7 \pm 1.9$ & $96.0 \pm 0.0$ \\
\hline Hatching rate (\%) & $93.3 \pm 2.3$ & $95.8 \pm 7.2$ & $94.6 \pm 2.5$ & $88.0 \pm 12.0$ & $93.3 \pm 4.6^{\mathrm{a}}$ & $86.7 \pm 10.1^{\mathrm{a}}$ & $28.0 \pm 26.2^{b}$ & $1.3 \pm 2.3^{\mathrm{bc}}$ & $96.0 \pm 4.0^{\mathrm{a}}$ & $1.3 \pm 2.3^{\mathrm{bc}}$ & $0.0 \pm 0.0^{c}$ \\
\hline Larval survival (\%) & $100.0 \pm 0.0$ & $98.6 \pm 2.4$ & $98.0 \pm 2.8$ & $100.0 \pm 0.0$ & $100.0 \pm 0.0$ & $98.5 \pm 2.6$ & $80.2 \pm 21.6$ & I & $100.0 \pm 0.0$ & l & l \\
\hline $\begin{array}{l}\text { Sub-lethal toxicity } \\
\text { Heartbeat (beat } \min ^{-1} \text { ) } \\
\text { Non-inflated swim } \\
\text { bladder }(\%)\end{array}$ & $\begin{array}{l}112.6 \pm 3.2 \\
64.4 \pm 23.4\end{array}$ & $112.3 \pm 4.8$ & $116.6 \pm 3.1$ & $120.5 \pm 3.3$ & $114.1 \pm 4.0$ & $117.2 \pm 8.2$ & $\begin{array}{l}118.1 \pm 7.9 \\
56.7 \pm 23.6\end{array}$ & $109.4 \pm 4.5$ & $\begin{array}{l}116.1 \pm 4.4 \\
64.4 \pm 10.2\end{array}$ & $\begin{array}{l}117.8 \pm 2.9 \\
/\end{array}$ & $\begin{array}{l}105.5 \pm 8.0 \\
/\end{array}$ \\
\hline Hatching $\mathrm{T}_{1 / 2}$ (day) & $10.8 \pm 0.1^{A}$ & $11.2 \pm 0.3^{\mathrm{AB}}$ & $11.1 \pm 0.1^{A}$ & $11.9 \pm 0.3^{B}$ & $10.2 \pm 0.1$ & $10.2 \pm 0.2$ & $10.4 \pm 0.1$ & I & $10.4 \pm 0.1$ & I & / \\
\hline Total length (mm) & $4.46 \pm 0.05^{A}$ & $4.47 \pm 0.02^{\mathrm{AB}}$ & $4.46 \pm 0.06^{\mathrm{AB}}$ & $4.25 \pm 0.0^{B}$ & $4.64 \pm 0.07^{\mathrm{a}}$ & $4.32 \pm 0.12^{\mathrm{b}}$ & $3.91 \pm 0.01^{\mathrm{c}}$ & l & $4.35 \pm 0.05^{b}$ & l & I \\
\hline Head length (mm) & $0.92 \pm 0.02$ & $0.92 \pm 0.02$ & $0.91 \pm 0.02$ & $0.92 \pm 0.02$ & $0.97 \pm 0.03^{\mathrm{a}}$ & $0.92 \pm 0.03^{\mathrm{ab}}$ & $0.89 \pm 0.05^{b}$ & l & $0.93 \pm 0.01^{a b}$ & l & I \\
\hline Yolk sac area $\left(\mathrm{mm}^{2}\right)$ & $0.48 \pm 0.03$ & $0.45 \pm 0.02$ & $0.44 \pm 0.04$ & $0.43 \pm 0.02$ & $0.40 \pm 0.03^{a b}$ & $0.39 \pm 0.02^{a b}$ & $0.31 \pm 0.01^{\mathrm{a}}$ & l & $0.40 \pm 0.04^{b}$ & l & / \\
\hline Deformed larvae (\%) & $9.0 \pm 3.7^{\mathrm{A}}$ & $11.1 \pm 3.8^{\mathrm{AB}}$ & $22.2 \pm 3.8^{B}$ & $62.2 \pm 7.7^{\mathrm{C}}$ & $17.8 \pm 7.7^{\mathrm{a}}$ & $48.9 \pm 16.8^{b}$ & $100.0 \pm 0.0^{c}$ & I & $33.3 \pm 6.7^{\mathrm{ab}}$ & l & I \\
\hline Abnormalities (score /5) & $0.1 \pm 0.1^{\mathrm{A}}$ & $0.1 \pm 0.0^{A}$ & $0.4 \pm 0.1^{\mathrm{B}}$ & $1.1 \pm 0.1^{\mathrm{C}}$ & $0.2 \pm 0.2^{\mathrm{a}}$ & $0.7 \pm 0.3^{\mathrm{ab}}$ & $3.1 \pm 0.3^{b}$ & I & $0.4 \pm 10.2^{a b}$ & l & I \\
\hline \multicolumn{12}{|l|}{ Abnormalities (\%) } \\
\hline Edema & $0.0 \pm 0.0^{A}$ & $0.0 \pm 0.0^{A}$ & $2.2 \pm 3.8^{A}$ & $17.8 \pm 0.1^{\mathrm{B}}$ & $0.0 \pm 0.0^{\mathrm{a}}$ & $2.2 \pm 3.8^{\mathrm{a}}$ & $60.6 \pm 8.6^{b}$ & I & 3.2.2 $\pm 3.8^{\mathrm{a}}$ & I & l \\
\hline Spinal & $2.2 \pm 3.8$ & $4.4 \pm 7.7$ & $13.3 \pm 6.7$ & $20.0 \pm 7.7$ & $11.1 \pm 7.7^{\mathrm{a}}$ & $24.4 \pm 20.4^{\mathrm{a}}$ & $65.2 \pm 2.1^{b}$ & l & $4.4 \pm 3.8^{\mathrm{a}}$ & / & l \\
\hline Craniofacial & $4.6 \pm 4.0^{A}$ & $6.7 \pm 6.7^{\mathrm{A}}$ & $13.3 \pm 0.0^{A}$ & $46.7 \pm 17.6^{B}$ & $8.9 \pm 10.2^{\mathrm{a}}$ & $24.4 \pm 7.7^{\mathrm{ab}}$ & $95.5 \pm 6.4^{\mathrm{b}}$ & l & $24.4 \pm 3.8^{\mathrm{ab}}$ & l & l \\
\hline Eye & $2.2 \pm 3.8$ & $0.0 \pm 0.0$ & $2.2 \pm 3.8$ & $0.0 \pm 0.0$ & $0.0 \pm 0.0$ & $2.2 \pm 3.8$ & $0.0 \pm 0.0$ & l & $0.0 \pm 0.0$ & l & / \\
\hline Cardio-vascular & $2.2 \pm 3.8^{\mathrm{A}}$ & $0.0 \pm 0.0^{A}$ & $8.9 \pm 3.8^{\mathrm{A}}$ & $28.9 \pm 13.9^{B}$ & $2.2 \pm 3.8 \mathrm{a}$ & $17.8 \pm 3.8^{\mathrm{ab}}$ & $90.9 \pm 12.9^{b}$ & 1 & $8.9 \pm 7.7^{\mathrm{ab}}$ & 1 & 1 \\
\hline
\end{tabular}


Table 3. Toxic equivalencies (TEQ) calculated for the three PAH fractions according to BaP or dioxin.

\begin{tabular}{lll}
\hline PAH fraction & TEQ / BaP & \\
\hline PY & 13.3 & TEQ / dioxin $^{\mathbf{b}}$ \\
LO & 0.8 & 0.032 \\
HO & 7.5 & 0.002 \\
\hline a (INERIS 2003 ${ }^{b}($ Barron & 0.009 \\
\hline
\end{tabular}

${ }^{a}$ (INERIS 2003) ${ }^{b}$ (Barron et al. 2004b) 
Table 4. Comparative toxicity of the three PAH fractions between Rainbow trout and Japanese medaka. Values refer to the lowest PAH sediment concentration causing a significant effect to the fish ELS (LOEC). PAH concentrations include the sum of 21 non-substituted PAHs, methyl naphtalenic and methyl phenanthrenic compounds.

\begin{tabular}{|c|c|c|c|c|c|c|}
\hline & \multicolumn{3}{|c|}{ Rainbow trout (Le Bihanic et al. submitted-a) } & \multicolumn{3}{|c|}{ Japanese medaka (This study) } \\
\hline \multicolumn{7}{|l|}{ Parameters } \\
\hline Concentrations tested & \multicolumn{3}{|c|}{$0.3 \mathrm{X}$ and $1 \mathrm{X}$} & \multicolumn{3}{|c|}{$0.3 \mathrm{X}, 1 \mathrm{X}$ and $3 \mathrm{X}$} \\
\hline Exposure matrix & \multicolumn{3}{|l|}{ Gravel } & \multicolumn{3}{|c|}{ Artificial sediment } \\
\hline Time of exposure & \multicolumn{3}{|c|}{ From eyed stage until hatching } & \multicolumn{3}{|c|}{ From fecundation until hatching } \\
\hline Temperature & \multicolumn{3}{|l|}{$10^{\circ} \mathrm{C}$} & \multicolumn{3}{|l|}{$26^{\circ} \mathrm{C}$} \\
\hline Photoperiod & \multicolumn{3}{|l|}{ Full dark } & \multicolumn{3}{|l|}{$12: 12$} \\
\hline Water renewal & \multicolumn{3}{|c|}{ No renewal } & \multicolumn{3}{|c|}{ Daily renewal } \\
\hline Salinity & \multicolumn{3}{|l|}{0 PSU } & \multicolumn{3}{|l|}{$5 \mathrm{PSU}$} \\
\hline $\operatorname{LOEC}\left(\mu \mathrm{g} \mathrm{g}^{-1} \mathrm{dw}\right)$ & PY & LO & HO & PY & LO & HO \\
\hline Survival & - & - & - & - & - & - \\
\hline Hatching success & - & - & $4.8(1 \mathrm{X})$ & - & $3.6(1 \mathrm{X})$ & $4.0(1 \mathrm{X})$ \\
\hline Larvae total length & - & $0.7(0.3 \mathrm{X})$ & $1.3(0.3 \mathrm{X})$ & $11.8(3 \mathrm{X})$ & $0.5(0.3 \mathrm{X})$ & $0.7(0.3 \mathrm{X})$ \\
\hline Abnormal larvae & $4.2(1 \mathrm{X})$ & $0.7(0.3 \mathrm{X})$ & $1.3(0.3 \mathrm{X})$ & $11.8(3 \mathrm{X})$ & $0.5(0.3 \mathrm{X})$ & - \\
\hline Comet assay & - & $4.1(1 \mathrm{X})$ & $1.3(0.3 \mathrm{X})$ & - & - & - \\
\hline Micronucleus assay & - & - & - & $0.8(0.3 \mathrm{X})$ & $0.5(0.3 \mathrm{X})$ & \\
\hline
\end{tabular}

